\title{
Measuring behaviours for escaping from house fires: use of latent variable models to summarise multiple behaviours
}

\author{
G. B. Ploubidis ${ }^{1 *}$, P. Edwards' ${ }^{1}$ D. Kendrick ${ }^{2}$ and on behalf of the Keeping Children Safe Study Group
}

\begin{abstract}
Background: This paper reports the development and testing of a construct measuring parental fire safety behaviours for planning escape from a house fire.

Methods: Latent variable modelling of data on parental-reported fire safety behaviours and plans for escaping from a house fire and multivariable logistic regression to quantify the association between groups defined by the latent variable modelling and parental-report of having a plan for escaping from a house fire. Data comes from 1112 participants in a cluster randomised controlled trial set in children's centres in 4 study centres in the UK.
\end{abstract}

Results: A two class model provided the best fit to the data, combining responses to five fire safety planning behaviours. The first group ('more behaviours for escaping from a house fire') comprised $86 \%$ of participants who were most likely to have a torch, be aware of how their smoke alarm sounds, to have external door and window keys accessible, and exits clear. The second group ('fewer behaviours for escaping from a house fire') comprised $14 \%$ of participants who were less likely to report these five behaviours. After adjusting for potential confounders, participants allocated to the'more behaviours for escaping from a house fire group were 2.5 times more likely to report having an escape plan (OR 2.48; 95 \% Cl 1.59-3.86) than those in the "fewer behaviours for escaping from a house fire" group.

Conclusions: Multiple fire safety behaviour questions can be combined into a single binary summary measure of fire safety behaviours for escaping from a house fire. Our findings will be useful to future studies wishing to use a single measure of fire safety planning behaviour as measures of outcome or exposure.

Trial registration number: NCT 01452191. Date of registration 13/10/2011

Keywords: Fire escape plans, Fire safety planning behaviours, Latent variable models, Methods

\section{Background}

Globally fire-related burns resulted in around 96,000 deaths in children and young people aged under 20 years in 2004 [1] and they are the 11th leading cause of death in children aged 1-9 years [1]. While most fire-related deaths occur in low and middle-income countries [1], they remain an important public health problem in high income countries. House fires are an important public health problem in Great Britain, with more than 43,000

\footnotetext{
*Correspondence: george.ploubidis@lshtm.ac.uk

${ }^{1}$ London School of Hygiene and Tropical Medicine, Room 150, Keppel

Street, London WC1E 7HT, UK

Full list of author information is available at the end of the article
}

occurring in 2011/12, resulting in 287 deaths and 11,300 casualties across all ages [2]. There steep social gradients in fire-related deaths in childhood; children of parents who have never worked or are long-term unemployed have fire-related death rates 38 times higher than those with parents in higher managerial or professional occupations [3]. Data from the USA demonstrates smoke alarms are associated with a two to threefold lower risk of death in house fires $[4,5]$ and household smoke alarm ownership has increased in Britain from $8 \%$ in 1988 to $86 \%$ in 2008 [2]. Given high levels of smoke alarm ownership, the emphasis of community fire safety is shifting towards the development of plans to help people escape safely from dwelling fires. In the UK, most Fire 
and Rescue Services offers free home fire safety checks, including help to develop a plan for escaping from a house fire [6]. More than 770,000 homes in England received a home fire safety check in 2011-12 [7].

Few published studies have evaluated the impact of interventions promoting planning for escaping from a house fire. A recent systematic review found only four studies evaluating home safety interventions that reported having or practising a plan for escaping from a house fire as an outcome measure [8-11]. Meta-analysis of these studies found home safety education was effective in increasing the proportion of families with a plan for escaping from a house fire [12], but this proportion remained relatively low post intervention, ranging across studies from $30 \%$ [10] to $63 \%$ [11]. Furthermore, none of the studies defined what a plan for escaping from a house fire consisted of, and all used single item questions to assess whether the family had, or had practised, a plan.

We are currently conducting a cluster randomised controlled trial evaluating a fire safety intervention delivered by children's centres in England to families with a child aged under 3 years. The primary outcome measure for the trial is whether the family reports having a plan for escaping from a house fire. We also measure self-reported behaviours which may form elements of a plan for escaping from a house fire, such as knowing how the smoke alarm sounds, keeping a torch next to the bed, making sure exits are clear, and that the keys for the external doors and windows are readily available [13]. This paper reports the development and testing of a construct measuring parental fire safety behaviours for planning escape from a house fire.

\section{Methods}

Home safety questionnaires often contain multiple questions about the same construct (e.g. asking families about owning a smoke alarm and about owning a fire extinguisher, two elements of the construct of fire safety). In situations such as this, statistical data reduction methods which allow multi-dimensional data sets to be made smaller, without any loss of information, may be useful. We used latent variable models as a data reduction technique to derive a single summary measure of behaviours for planning escape from a house fire.

\section{Sample and measures}

The study sample included 1112 families from children's centres in four sites (Nottingham, Bristol, Norwich and Newcastle, UK), who were participating in a cluster randomised controlled trial evaluating a fire safety intervention. Children's centres were invited to participate if their catchment area had more than $50 \%$ of under- 5 year-olds living in one of the $30 \%$ most disadvantaged super output areas in England. Families living in the catchment area were eligible if they had attended the centre in the previous 3 months; if the parents were aged 16 years or older and if they had a child aged 0-2 years. Children's centres were stratified by trial site (4 strata) and randomly allocated within strata to treatment arms [(a) usual care, (b) fire safety injury prevention briefing and (c) fire safety injury prevention briefing plus facilitation to implement the briefing] using permuted block randomisation, with a block size of 3 . The allocation schedule was produced by an independent statistician, using the Stata randomisation algorithm. Allocations were placed in sequentially numbered opaque envelopes (one set for each trial site). Information was collected on socio-demographic characteristics and fire safety behaviours of participants using a self-completed questionnaire at recruitment to the trial. Questionnaires were administered by post, telephone and face-face, depending on the method preferred by the children's centre and the response rate. Families that completed a questionnaire were provided with a $£ 5$ gift voucher. Characteristics of participants are presented in Table 1 and fire safety behaviours in Table 2 .

\section{Statistical methods}

A latent variable model is any model that includes unobserved random variables. The latent variable is not part of the dataset, in that it is not observed, but it is specified in order to account for any associations between the observed variables. Latent variable models combine information from different observed variables without making assumptions about units of measurement, and they also allow assessment of reliability and validity of these variables $[14,15]$. To an increasing extent, latent variable modelling has been recognized as a valuable tool in epidemiological research [15] and numerous studies have employed latent variables to reduce a large number of observations and derive meaningful summaries. Other areas of application include survival analysis, meta-analysis, disease mapping, biometrical genetics, covariate measurement error models and joint models for longitudinal change and dropout.

There are two broad categories of latent variable models: dimensional models, where the latent variable is continuous and individuals are ranked (also called factor analysis or item response models); and discrete models, where the latent variable is categorical and individuals are grouped (also called latent class models). Hybrid models where both continuous and discrete latent variables are used are also available but their use is beyond the scope of this paper. 
Table 1 Characteristics of participants

\begin{tabular}{|c|c|c|}
\hline & $\mathbf{n}$ & $\%$ \\
\hline \multicolumn{3}{|c|}{ Number of smokers in household } \\
\hline 0 & 759 & 70.1 \\
\hline 1 & 226 & 20.9 \\
\hline 2 & 97 & 8.0 \\
\hline \multicolumn{3}{|c|}{ Number of adults in household } \\
\hline 1 & 192 & 18.0 \\
\hline 2 & 810 & 75.8 \\
\hline 3 or more & 67 & 6.2 \\
\hline \multicolumn{3}{|c|}{ Number of children in household } \\
\hline 1 & 542 & 50.6 \\
\hline 2 & 351 & 32.8 \\
\hline 3 & 121 & 11.3 \\
\hline 4 or more & 57 & 5.3 \\
\hline \multicolumn{3}{|c|}{ Age of youngest child } \\
\hline Under 1 year & 484 & 44.5 \\
\hline $1-2$ years & 603 & 55.5 \\
\hline \multicolumn{3}{|c|}{ Mother aged 16-20 } \\
\hline Yes & 54 & 5.1 \\
\hline No & 1006 & 94.9 \\
\hline \multicolumn{3}{|c|}{ Heavy drinker in household ${ }^{a}$} \\
\hline Yes & 592 & 58.5 \\
\hline No & 420 & 41.5 \\
\hline \multicolumn{3}{|c|}{ English as 1st language } \\
\hline Yes & 1004 & 91.3 \\
\hline No & 96 & 8.7 \\
\hline \multicolumn{3}{|l|}{ Ethnic group } \\
\hline White British & 952 & 89.6 \\
\hline Other & 111 & 11.4 \\
\hline \multicolumn{3}{|l|}{ IMD score ${ }^{b}$} \\
\hline Mean & 31.73 & \\
\hline Std deviation & 16.64 & \\
\hline Minimum & 2.36 & \\
\hline Maximum & 74.8 & \\
\hline
\end{tabular}

Not applicable and missing responses are excluded for all variables

a Heavy drinker defined as drinks $\geq 6$ drinks on a typical day when they have an alcoholic drink

b IMD—Index of Multiple Deprivation 2010 version [27]

We first used a dimensional model to create a continuous latent plan for escaping from a house fire summary measure based on a combination of binary and ordinal fire safety variables. These comprised responses from seven questions asking about fire safety relevant to planning escape from a house fire (Table 2). To find the fire safety variables most compatible to the data latent structure, we used a discrete latent variable model to derive a categorical summary measure of behaviour for planning escape from a house fire, where individuals are grouped.
Due to the binary and ordinal nature of the fire safety behaviour variables, in both approaches two parameter binary and ordinal logistic link functions were used.

In the dimensional models, 'factor loadings' represent the strength of the association between the fire safety variable and the latent plan for escaping from a house fire summary measure (and may be interpreted as correlations). 'Thresholds' represent the level of the latent plan for escaping from a house fire summary measure that must be reached for a specific response ("three days a week" for example) in a categorical or ordinal fire safety variable to be given. Each individual is assigned a score on each dimension, these scores in theory range from $-\infty$ to $+\infty$, but in most applications the range is from -3 to 3 .

In discrete models, "posterior or conditional item probabilities" represent the probability, conditional on group membership, of a category of an observed variable (having a torch for example) being given. Class probabilities specify the relative size of each class, or population prevalence of each group. Group membership is based on the observed response pattern of items under an important assumption, called the conditional or local independence assumption, which implies that the correlation among the observed variables is explained by the latent categorical variable [16].

There are a range of tests that can be used to assess how well the model fits the data with different tests for dimensional and latent class models. Statistics for these measures are given in Tables 5 and 6, along with the values which suggest a good fit of the models to the data for each approach. All models were estimated with the "complex survey design" option in the Mplus 7.0 software [17] which accommodates complex sampling designs and returns robust parameter estimates taking into account dependence due to clustering.

As an external validation criterion for our binary summary measure, we used a question from the same questionnaire in which participants were asked whether they had a plan for escaping from a house fire. Using a multivariable logistic regression model we estimated the association between parents reporting that they had a plan for escaping from a house fire and the binary summary measure, adjusting for a range of confounding variables (as listed in Table 4).

\section{Ethical approval}

Ethical approval was provided by the NRES East Midlands Committee (Derby), reference number 11/ $\mathrm{EM} / 0011$.

Trial registration number: NCT 01452191. Date of registration $13 / 10 / 2011$ 
Table 2 Frequency of fire safety behaviours

\begin{tabular}{|c|c|c|}
\hline & $n$ & $\%$ \\
\hline \multicolumn{3}{|l|}{ Has torch } \\
\hline Yes & 347 & 31.9 \\
\hline No & 741 & 68.1 \\
\hline \multicolumn{3}{|c|}{ Knows sound of alarm } \\
\hline Yes & 1006 & 97.7 \\
\hline No & 24 & 2.3 \\
\hline \multicolumn{3}{|c|}{ External door keys accessible } \\
\hline Never & 67 & 6.2 \\
\hline$\leq 1$ day/week & 47 & 4.3 \\
\hline 2-3 days/week & 25 & 2.3 \\
\hline 4-5 days/week & 16 & 1.5 \\
\hline 6-7 days/week & 926 & 85.7 \\
\hline \multicolumn{3}{|c|}{ Window keys accessible } \\
\hline Never & 145 & 13.7 \\
\hline$\leq 1$ day/week & 75 & 7.1 \\
\hline 2-3 days/week & 26 & 2.5 \\
\hline 4-5 days/week & 14 & 1.3 \\
\hline 6-7 days/week & 796 & 75.4 \\
\hline \multicolumn{3}{|l|}{ Exits clear } \\
\hline Never & 86 & 8.1 \\
\hline$\leq 1$ day/week & 51 & 4.8 \\
\hline 2-3 days/week & 44 & 4.2 \\
\hline 4-5 days/week & 40 & 3.8 \\
\hline 6-7 days/week & 838 & 79.1 \\
\hline \multicolumn{3}{|c|}{ Child might hide under bed } \\
\hline Strongly agree & 281 & 32.8 \\
\hline Agree & 27 & 3.2 \\
\hline Neither & 71 & 8.3 \\
\hline Disagree & 218 & 25.5 \\
\hline Strongly disagree & 259 & 30.3 \\
\hline \multicolumn{3}{|c|}{ Child might hide in cupboard/wardrobe } \\
\hline Strongly agree & 278 & 32.4 \\
\hline Agree & 23 & 2.7 \\
\hline Neither & 51 & 5.9 \\
\hline Disagree & 233 & 27.1 \\
\hline Strongly disagree & 274 & 31.9 \\
\hline
\end{tabular}

Not applicable and missing responses are excluded for all variables

\section{Results}

A total of 347 (32\%) of the participants reported that they had a torch beside the bed and 1006 (98\%) reported that they were familiar with the sound of their alarm. A total of 838 (79\%) participants reported that they kept their exit routes clear, 926 (86\%) that they had the external door keys and 796 (75 \%) that they had window keys in accessible places on at least 6 days per week, 308 (36\%) strongly agreed or agreed that, in the event of a fire, their child might hide under the bed and 301 (35\%) that their child might hide in a cupboard or wardrobe (Table 2).
First we used dimensional models to derive a continuous summary measure of behaviour for planning escape from a house fire behaviour from the seven fire safety variables. Since we had no a priori hypothesised structure for the data we estimated a sequence of exploratory models (using exploratory factor analysis) [18], with each model containing a different number of dimensions. A two-factor model (Fig. 1) was the best fitting dimensional model (see Table 5 in Appendix) which was confirmed by a confirmatory factor analysis. In the diagram $\mathrm{f} 1$ and $\mathrm{f} 2$ represent the continuous latent factors (dimensions) and the rectangles represent the observed fire safety variables.

Having external door and window keys accessible and keeping exits clear were the strongest indicators of the first plan for escaping from a house fire dimension The second plan for escaping from a house fire dimension comprised only two (highly loading) variables related to the likelihood that children may hide under a bed, or in a cupboard, in the event of a fire. The first and second plan for escaping from a house fire dimensions were not correlated with each other, suggesting their component questions were measuring different constructs. As the second dimension included only two variables unrelated to the first dimension (which included variables most relevant to planning for escape from a house fire), we excluded the variables indicating whether a child might hide from further analysis.

Secondly we used discrete models to derive a categorical summary measure of plan for escaping from a house fire behaviour. A two class model provided the best fit to the data (see Table 6 in Appendix). Table 3 presents the posterior probabilities for each fire safety variable for the two groups. The first group ('more behaviours for escaping from a house fire) comprised $87 \%$ of participants who were most likely to have a torch, and to report that they were aware of how their smoke alarm sounds. They were

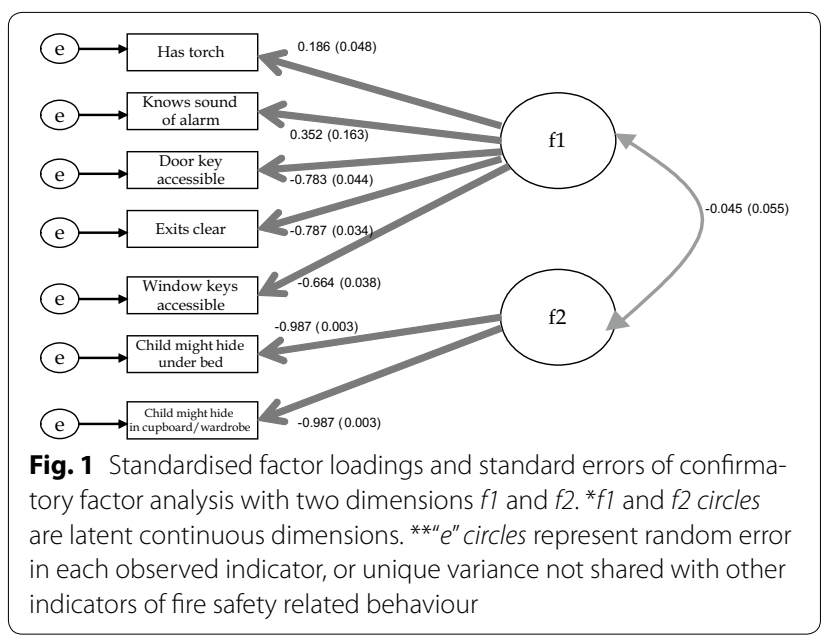


Table 3 Posterior probabilities derived from categorical latent variable model

\begin{tabular}{|c|c|c|}
\hline & $\begin{array}{l}\text { Class } 1-\text { more } \\
\text { behaviours for } \\
\text { escaping from } \\
\text { a house fire }\end{array}$ & $\begin{array}{l}\text { Class 2-fewer } \\
\text { behaviours } \\
\text { for escaping } \\
\text { from a house fire }\end{array}$ \\
\hline \multicolumn{3}{|l|}{ Has torch } \\
\hline Yes & 0.334 & 0.223 \\
\hline No & 0.666 & 0.777 \\
\hline \multicolumn{3}{|c|}{ Knows sound of alarm } \\
\hline Yes & 0.982 & 0.944 \\
\hline No & 0.018 & 0.056 \\
\hline \multicolumn{3}{|c|}{ External door keys accessible } \\
\hline Never & 0.037 & 0.225 \\
\hline$\leq 1$ day/week & 0.009 & 0.265 \\
\hline 2-3 days/week & 0.005 & 0.143 \\
\hline 4-5 days/week & 0.008 & 0.059 \\
\hline 6-7 days/week & 0.942 & 0.308 \\
\hline \multicolumn{3}{|l|}{ Exits clear } \\
\hline Never & 0.051 & 0.276 \\
\hline$\leq 1$ day/week & 0.005 & 0.328 \\
\hline 2-3 days/week & 0.021 & 0.177 \\
\hline 4-5 days/week & 0.034 & 0.061 \\
\hline 6-7 days/week & 0.889 & 0.158 \\
\hline \multicolumn{3}{|c|}{ Window keys accessible } \\
\hline Never & 0.095 & 0.403 \\
\hline$\leq 1$ day/week & 0.033 & 0.310 \\
\hline 2-3 days/week & 0.010 & 0.114 \\
\hline 4-5 days/week & 0.011 & 0.028 \\
\hline 6-7 days/week & 0.850 & 0.144 \\
\hline
\end{tabular}

Table 4 Odds ratios (with $95 \%$ Cls) for reporting having a plan for escaping from a house fire according to whether allocated to the 'more behaviours for escaping from a house fire' group (adjusted for all confounders presented in the table)

\begin{tabular}{ll}
\hline & Odds ratio $(95 \% \mathrm{Cl})$ \\
\hline More behaviours for escaping from a house fire & $2.48(1.59-3.86)$ \\
$>2$ smokers in household & $0.67(0.43-1.07)$ \\
$>2$ adults in household & $1.34(0.52-3.44)$ \\
$>2$ children in household & $0.35(0.21-0.60)$ \\
Youngest child 1-2 years old & $0.97(0.77-1.22)$ \\
Mother $>20$ years old & $0.99(0.62-1.60)$ \\
Heavy drinker in household & $0.87(0.69-1.10)$ \\
English not first language & $1.08(0.65-1.78)$ \\
Non-white ethnic group & $1.05(0.62-1.80)$ \\
Index of multiple deprivation score & $0.99(0.98-1.01)$ \\
\hline
\end{tabular}

also more likely to have door and window keys accessible, and to have exits clear. For example, a typical member of this group has responded that they have a torch and are aware how their smoke alarm sounds, they have accessible door and window keys more than 2-3 times per week and have exits clear more than 4-5 times a week.

By contrast, the second group ('fewer behaviours for escaping from a house fire) comprised $13 \%$ of participants who were less likely to have a torch, and less likely to be aware of how their smoke alarm sounds. They were also less likely to have door and window keys accessible, and less likely to have exits clear. A typical member of this group does not have a torch, is not aware of how their smoke alarm sounds, has accessible door and window keys less than 1 day a week, and has exits clear less than 1 day a week.

A binary summary plan for escaping from a house fire measure ('more behaviours for escaping from a house fire' vs. 'fewer behaviours for escaping from a house fire') based on the two group latent class model results was derived. Using a multivariable logistic regression model we estimated the association between parents reporting that they had a plan for escaping from a house fire and the binary summary measure (Table 4). After adjusting for potential confounders, participants allocated to the 'more behaviours for escaping from a house fire group were 2.5 times more likely to report having a plan for escaping from a house fire than those in the 'fewer behaviours for escaping from a house fire' group (OR 2.48; $95 \%$ CI 1.59-3.86).

\section{Discussion \\ Main findings}

We have shown that multiple questions asking about behaviours for escaping from a house fire can be combined into a single binary summary measure, which provides a good fit to the data from the individual questions and it has been externally validated by comparing with a self-reported measure of having a plan for escaping from a house fire. Our findings suggest questions on having a torch beside the bed, knowing the sound of the smoke alarm, keeping exits clear and keeping door and window keys accessible appear to assess component elements of a plan for escaping from a house fire. Our findings will be useful to future studies wishing to use a single measure of planning for escape from a house fire as measures of outcome or exposure.

\section{Strengths and limitations}

To our knowledge this is the first published paper describing the development of a measure of planning for escape from a house fire. Previous studies [8-11] have reported only single-item measures asking whether families had, or had practised a plan for escaping from a house fire. Our measure is more comprehensive than these as it uses information on range of behaviours relevant to 
escaping from a house fire. As we also asked families whether they had a plan for escaping from a house fire we were able to validate our newly developed measure against the reports of having a plan for escaping from a house fire, including adjusting for possible confounders. However, the reports of having an escape plan were collected on the same questionnaire as the individual items and are not therefore independent. To provide a better external validation, we would have collected reports of escape plans on a different occasion to when the questionnaire was administered.

Our multivariable model found that families with more than 2 children were less likely to report having a plan for escaping from a house fire. It is plausible that making a plan to escape from a house fire is more difficult in larger families, as there are more children (likely to be at different developmental stages) to plan for and to explain and practise the plan with. The purpose of this analysis was to provide some validation of our summary measure, not to explore factors associated with having a plan to escape a house fire. This finding should therefore be interpreted with caution and requires replication in other studies.

Our behaviours for planning escape from a house fire were self-reported, with most questions asking about the frequency of behaviours and one question asking about knowledge of how smoke alarms sound. Validating these, for example, by home observations, is not possible, and to our knowledge there are no published studies reporting reliability or validity of these measures [19-26]. Two studies have reported some measures of reliability and validity of self-reported plans for escaping from a house fires. The first found a high level of agreement (91 \%; no kappa coefficients reported) to repeat administration (over 14-24 days) of a single item question (Do you have a plan for escape from the home in the event of a fire?) as part of a general home safety survey amongst 35 parents of children aged 1-4 years [21]. This question is very similar to that asked in our trial, suggesting the test-retest reliability of our question about having a plan for escaping from a house fire may be reasonable. An Australian study reported no significant difference in reported prevalence of having a fire evacuation plan on a telephone survey and home observation, although they did not report the percentage agreement, kappa coefficients, sensitivity, specificity or predictive values [20]. It is possible that parents in our study over-reported behaviours they perceived to be socially acceptable. This could affect our findings if over-reporting varied substantially between the safety behaviours comprising our summary binary measure, although there is no reason to believe some of these safety behaviours are much more socially acceptable than others.
Our study was restricted to families with young children attending children's centres in England. Children's centres provide integrated early years health, social care and education to families living in disadvantaged areas. So, whilst our findings are applicable to families whose children are at greater risk of fire-related injury, they may not be generalisable to families with older children, more advantaged populations, to those from low and middleincome countries, or to planning for escaping from a house fires amongst other vulnerable populations such as the elderly or disabled.

The distribution of the first plan for escaping from a house fire dimension was highly skewed and resembled a mixture of distributions rather than a continuum. Using this distribution even with appropriate link functions as an outcome in predictive models would have been potentially biased since the two suspected mixture components may be associated with different sets of predictors. We therefore decided to use a categorical latent variable model to create our single summary measure.

\section{Implications for research and practice}

Our findings will be useful for future studies in high income countries where planning for escape from a house fire will be similar to that in the UK and for populations comprising families with small children. Such studies can use our questions to develop a single summary measure of fire escape planning behaviour. Many injury prevention interventions are evaluated using tools which measure multiple safety behaviours. The methods we describe could be used to develop single outcome measures for evaluation studies, or single measures of exposures for observational studies. This may be helpful in minimising the risk of "spuriously" significant findings resulting from multiplicity (statistical significance testing of multiple outcomes or exposures). Our findings will be of use to injury prevention practitioners who help families to develop plans for escaping from a house fire, as our questions could be used in home fire safety risk assessments or home safety check lists, and could be used by practitioners to assess the impact of their work on planning escape from house fires.

\section{Conclusion}

Multiple fire safety behaviour questions can be combined into a single binary summary measure of planning for escape from a house fire. Our findings will be useful to future studies wishing to use a single measure of behaviours for planning for escape from a house fire as measures of outcome or exposure.

\section{Authors' contributions}

GBP undertook the data analysis, contributed to interpretation of the data and to drafting the paper. PE contributed to the analysis and interpretation of the 
data and to drafting the paper. DK had the original idea for the trial, designed the trial, supervised data collection, contributed to the analysis and interpretation of the data and to drafting the paper. All authors read and approved the final manuscript.

\section{Author details}

${ }^{1}$ London School of Hygiene and Tropical Medicine, Room 150, Keppel Street, London WC1E 7HT, UK. ${ }^{2}$ Division of Primary Care, School of Medicine, Tower Building, University Park, Nottingham NG7 2RD, UK.

\section{Acknowledgements}

This paper presents independent research commissioned by the National Institute for Health Research (NIHR) under its Programme Grants for Applied Research funding scheme (RP-PG-0407-10231). The views expressed in this article are those of the authors and not necessarily those of the NHS, the NIHR or the Department of Health.

\section{Keeping Children Safe Study Group}

Joanne Ablewhite', Penny Benford', Clare Bryan'1, Rose Clacy', Carol Coupland ${ }^{1}$, Nicola Cooper ${ }^{2}$, Toity Deave ${ }^{3}$, Trudy Goodenough ${ }^{3}$, Adrian Hawkins ${ }^{4}$, Mike Hayes ${ }^{5}$, Paul Hindmarch ${ }^{4}$, Bryony Kay ${ }^{6}$, Benita Laird-Hopkins ${ }^{3}$, Gosia Majsak-Newman ${ }^{7}$, Elaine McColl ${ }^{8}$, Lisa McDaid ${ }^{7}$, Richard Reading ${ }^{9}$, Jane Stewart $^{1}$, Alex J Sutton ${ }^{2}$, Elizabeth Towner ${ }^{3}$, Michael Watson ${ }^{10}$, Persephone Wynn ${ }^{1}$

${ }^{1}$ Division of Primary Care, School of Medicine, Tower Building, University Park, Nottingham, NG7 2RD, UK UK

${ }^{2}$ Department of Health Sciences, University of Leicester, Leicester LE1 7RH,

${ }^{3}$ Centre for Child and Adolescent Health, Health and Life Sciences, University of the West of England, Bristol, Oakfield House, Oakfield Grove, Bristol BS8 2BN, UK

${ }^{4}$ Great North Children's Hospital, Research Unit Level 2, New Victoria Wing Royal Victoria Infirmary, Queen Victoria Road, Newcastle upon Tyne, NE1 4LP, UK

${ }^{5}$ Child Accident Prevention Trust, Canterbury Court (1.09), 1-3 Brixton Road London, SW9 6DE, UK

${ }^{6}$ Emergency Department, Bristol Royal Hospital for Children, Paul O'Gorman Building, Upper Maudlin Street, Bristol, BS2 8BJ

${ }^{7} \mathrm{NHS}$ Clinical Research and Trials Unit, Norwich Medical School, University of East Anglia, Norwich, NR4 7TJ, UK

${ }^{8}$ Newcastle Clinical Trials Unit, 4th Floor, William Leech Building, The Medical School, Newcastle University, Framlington Place, Newcastle upon Tyne, NE2 $4 \mathrm{HH}, \mathrm{UK}$

${ }^{9}$ Jenny Lind Paediatric Department, Norfolk and Norwich University Hospital, Colney Lane, Norwich, NR4 7UY, UK

${ }^{10}$ School of Health Sciences, University of Nottingham, D86, Queen's Medical Centre, Nottingham, NG7 2HA, UK

\section{Competing interests}

The authors declare that they have no competing interests.

\section{Appendix}

See Tables 5 and 6 and Fig. 2.

Table 5 Assessment of fit of dimensional latent variable models

\begin{tabular}{llllll}
\hline & $\boldsymbol{X}^{\mathbf{2}}$ & $\boldsymbol{p}$ & CFI & TLI & RMSEA \\
\hline $\begin{array}{l}\text { Exploratory factor analysis-1 } \\
\text { factor }\end{array}$ & 708.249 & 0.001 & 0.986 & 0.98 & 0.176 \\
$\begin{array}{l}\text { Exploratory factor analysis-2 } \\
\text { factors }\end{array}$ & 15.236 & 0.293 & 1 & 1 & 0.012 \\
$\begin{array}{l}\text { Confirmatory factor analysis-2 } \\
\text { factors }\end{array}$ & 9.998 & 0.762 & 1 & 1 & 0.001 \\
\hline
\end{tabular}

CF/ comparative Fit Index, values $>0.95$ indicate food fit

TL/ Tucker Lewis Index, values $>0.95$ indicate good fit

RMSEA root mean square error of approximation, values $<0.06$ indicate good fit
Table 6 Assessment of fit of categorical latent variable models-latent class analysis

\begin{tabular}{lllll}
\hline & -2LL & AIC & SSA-BIC & Entropy \\
\hline 1 Class & -3139.53 & 6307.05 & 6332.76 & 1 \\
2 Classes & -2950.85 & 5959.70 & 6012.96 & 0.84 \\
3 Classes & -2875.93 & 5839.86 & 5920.68 & 0.77 \\
4 Classes & -2820.53 & 5759.07 & 5867.43 & 0.84 \\
\hline
\end{tabular}

$-2 L L$ minus twice the loglikelihood, smaller values indicate better fit AIC akaike information criterion, smaller values indicate better fit

SSA BIC sample size adjusted bayesian information criterion, smaller values indicate better fit

Entropy values close to 1 indicate more reliable classification (lower classification error)

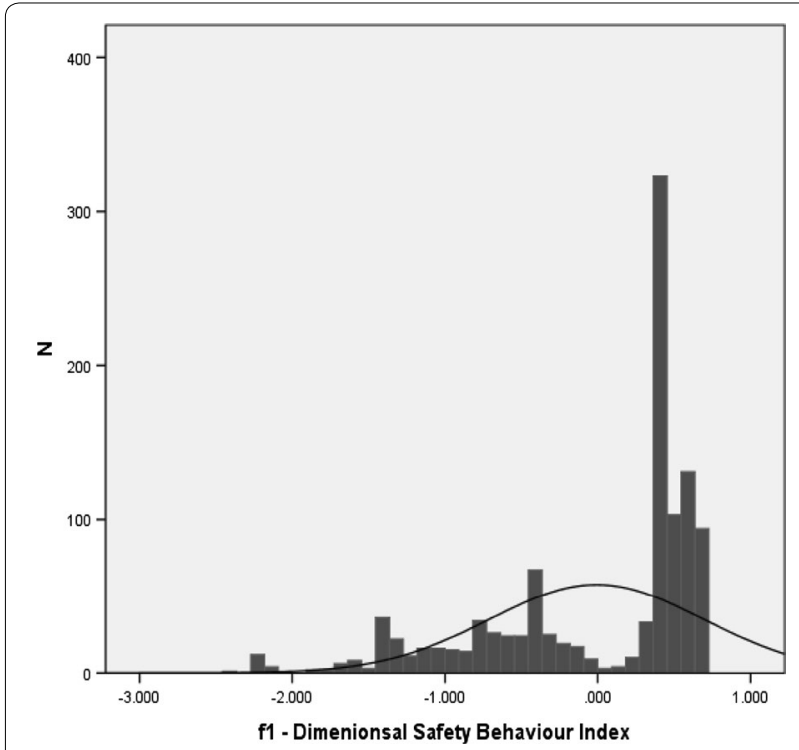

Fig. 2 Histogram of dimensional safety behaviour summary index $(f 7)$

Received: 28 January 2015 Accepted: 30 November 2015

Published online: 15 December 2015

\section{References}

1. Peden M, Oyegbite K, Ozanne-Smith J, Hyder A, Branche C, Rahman A, Rivara F, Bartolomeos K. World report on child injury prevention. In: World Health Organisation, UNICEF, Geneva. 2008.

2. Department for Communities and Local Government: Fire Statistics 2011 to 2012. In: London. 2012.

3. Edwards P, Roberts I, Green J, Lutchmun S. Deaths from injury in children and employment status in family: analysis of trends in class specific death rates. BMJ. 2006;333(7559):119-21.

4. Runyan CW, Bangdiwala SI, Linzer MA, Sacks JJ, Butts J. Risk factors for fatal residential fires. N Engl J Med. 1992;327(12):859-63.

5. Marshall SW, Runyan CW, Bangdiwala SI, Linzer MA, Sacks JJ, Butts JD. Fatal residential fires: who dies and who survives? JAMA J Am Med Assoc. 1998;279(20):1633-7.

6. http://www.fireservice.co.uk/safety/hfsc. Accessed 21 Aug 2013. 
7. Department for Communities and Local Government. FRS operational statistics bulletin for England 2011-12. London: FRS; 2012.

8. Campbell NR, Ayala GX, Litrownik AJ, Slymen DJ, Zavala F, Elder JP. Evaluation of a first aid and home safety program for hispanic migrant adolescents. Am J Prev Med. 2001;20(4):258-65.

9. Hwang V, Duchossois G, Garcia-Espana J, Durbin D. Impact of a community based fire prevention intervention on fire safety knowledge and behavior in elementary school children. Inj Prev. 2006;12(5):344-6.

10. Petridou E, Tolma E, Dessypris N, Trichopoulos D. A controlled evaluation of a community injury prevention project in two Greek islands. Int J Epidemiol. 1997;26(1):173-9.

11. Posner JC, Hawkins LA, Garcia-Espana F, Durbin DR. A randomised, clinical trial of a home safety intervention based in an Emergency Department setting. Pediatrics. 2004;113(6):1603-8.

12. Kendrick D, Young B, Mason-Jones AJ, llyas N, Achana FA, Cooper NJ, Hubbard SJ, Sutton AJ, Smith S, Wynn P et al: Home safety education and provision of safety equipment for injury prevention. Cochrane Database Syst Rev. 2012(9).

13. Communities and Local Government: http://www.direct.gov.uk/en/ groups/dg_digitalassets/@dg/@en/documents/digitalasset/dg_073993. pdf. Accessed 25 Aug 2013. In: Fire safety in the home. 2011.

14. Ploubidis GB, Grundy E. Health measurement in population surveys: combining information from self-reported and observer-measured health indicators. Demography. 2011:48(2):699-724.

15. Rabe-Hesketh S, Skrondal A. Classical latent variable models for medical research. Stat Methods Med Res. 2008;17(1):5-32.

16. Skrondal A, Rabe-Hesketh S. Generalized latent variable modeling: multilevel, longitudinal, and structural equation models. Boca Raton: Chapman and Hall/CRC; 2004.

17. Muthen LK, Muthen BO. Mplus user's guide. 7th edn. Los Angeles, CA. pp. 1998-2012
18. Gorsuch R. Factor analysis. 2nd ed. Hillsdale NJ: Lawrence Erlbaum Associates; 1983.

19. Hatfield PM, Staresinic AG, Sorkness CA, Peterson NM, Schirmer J, Katcher ML. Validating self reported home safety practices in a culturally diverse non-inner city population. Inj Prev. 2006;12(1):52-7.

20. Yorkston E, Turner C, Schluter P, McClure R. Validity and reliability of responses to a self-report home safety survey designed for use in a community-based child injury prevention programme. Int J Injr Contr Saf Promot. 2005;12(3):193-6.

21. Mason M, Kaufer Christoffel K, Sinacore J. Reliability and validity of the injury prevention project home safety survey. Arch Pediatr Adolesc Med. 2007;161(8):759-65.

22. Chen L-H, Gielen AC, McDonald EM. Validity of self reported home safety practices. Inj Prev. 2003;9(1):73-5.

23. Osborne JM, Shibl R, Cameron CM, Kendrick D, Lyons RA, Spinks AB, Sipe N, McClure RJ. Validity of parent's self-reported responses to home safety questions. Int J Injr Contr Saf Promot. 2015;1-11.

24. Watson MC, Benford P, Coupland CA, Clacy R, Hindmarsh P, MajsakNewman G, Deave T, Kendrick D. team obotKCSp: Validation of a home safety questionnaire used in a series of case control studies. Inj Prev. 2014;20(5):336-42.

25. Watson M, Kendrick D, Coupland D. Validation of a home safety questionnaire used in a randomised controlled trial. Inj Prev. 2003;9:180-3.

26. Clamp M, Kendrick D. A randomised controlled trial of general practitioner safety advice for families with children under 5 years. BMJ. 1998;316(7144):1576-9.

27. Department for Communities and Local Government: English Indices of Deprivation 2010. https://www.gov.uk/government/statistics/englishindices-of-deprivation-2010. Accessed 27 Feb 2015.

\section{Submit your next manuscript to BioMed Central and we will help you at every step:}

- We accept pre-submission inquiries

- Our selector tool helps you to find the most relevant journal

- We provide round the clock customer support

- Convenient online submission

- Thorough peer review

- Inclusion in PubMed and all major indexing services

- Maximum visibility for your research

Submit your manuscript at www.biomedcentral.com/submit
() Biomed Central 